\title{
Foreign language knowledge can influence native language performance in exclusively native contexts
}

\author{
JANET G. VAN HELL \\ University of Nijmegen, Nijmegen, The Netherlands \\ and \\ TON DIJKSTRA \\ NICI, University of Nijmegen, Nijmegen, The Netherlands
}

\begin{abstract}
In three experiments, we studied the influence of foreign language knowledge on native language performance in an exclusively native language context. Trilinguals with Dutch as their native and dominant language (L1), English as their second language (L2), and French as their third language (L3) performed a word association task (Experiment 1) or a lexical decision task (Experiments 2 and 3) in L1. The L1 stimulus words were cognates with their translations in English, cognates with their translations in French, or were noncognates. In Experiments 1 and 2 with trilinguals who were highly proficient in English and relatively low in proficiency in French, we observed shorter word association and lexical decision times to the L1 words that were cognates with English than to the noncognates. In these relatively low-proficiency French speakers, response times (RTs) for the L1 words that were cognates with French did not differ from those for the noncognates. In Experiment 3, we tested Dutch-EnglishFrench trilinguals with a higher level of fluency in French (i.e., equally fluent in English and in French). We now observed faster responses on the L1 words that were cognates with French than on the noncognates. Lexical decision times to the cognates with English were also shorter than those to the noncognates. The results indicate that words presented in the dominant language, to naive participants, activate information in the nontarget, and weaker, language in parallel, implying that the multilinguals' processing system is profoundly nonselective with respect to language. A minimal level of nontarget language fluency seems to be required, however, before any weaker language effects become noticeable in $\mathrm{L} 1$ processing.
\end{abstract}

Cognates are words in different languages that have the same meaning and are spelled, and often pronounced, in the same or in a similar way (e.g., Dutch and English water, or Dutch bakker and English baker). Does the fact that a word has a cognate translation influence a bilingual's response to that word, even if the bilingual performs in only one language? If the mental lexicon of a bilingual is organized by language, bilinguals might in principle activate only word candidates from the language that is contextually relevant (language-selective access). However,

J.G. van H. was partly supported by Grant 575-56-073 from the Dutch Organization for Scientific Research (NWO). Experiments 1 and 2 were conducted while the first author was affiliated with the Department of Psychology, University of Amsterdam, The Netherlands. We thank the department for providing the research facilities. We thank Natalie Snoeren for her help in running Experiment 3, and Sanne de Vries, Jolanda Fransen, and Joppe Deen for their contributions to Experiment 1. We are grateful to Ken Forster, David Green, François Grosjean, Judith Kroll, Karen Mansfield, and two anonymous reviewers for helpful comments on an earlier draft of the manuscript. Correspondence concerning this article may be addressed to J. G. van Hell, University of Nijmegen, Department of Special Education, P .O. Box 9104, 6500 HE Nijmegen, The Netherlands (e-mail: j.vanhell@ ped.kun.nl). if their mental lexicon is organized on the basis of item characteristics, words from both languages might be activated in response to incoming information (languagenonselective access). Taking this view to an extreme would imply that words from both languages are activated even when the bilinguals are performing in their native and dominant language and in a purely native language context. Such parallel activation might occur not only for cognates that have an identical orthography, but even for cognates that are only similar in orthography. This is the far-reaching issue that we will investigate in the present study.

In the past decade, many studies have been performed on how the bilingual lexicon is accessed in experimental settings in which words from different languages are mixed, or in which second-language words are targeted. An increasing number of studies indicate that, in these situations, the activation of words in bilingual memory operates in a language-nonselective way (e.g., Altenberg \& Cairns, 1983; Beauvillain \& Grainger, 1987; BijeljacBabic, Biardeau, \& Grainger, 1997; Brysbaert, Van Dyck, \& Van de Poel, 1999; De Groot, Delmaar, \& Lupker, 2000; De Groot \& Nas, 1991; Dijkstra, Grainger, \& Van 
Heuven, 1999; Dijkstra, Van Jaarsveld, \& Ten Brinke, 1998; Gollan, Forster, \& Frost, 1997; Grainger \& Beauvillain, 1987; Grainger \& Frenck-Mestre, 1998; Jared \& Kroll, 2001; Jiang, 1999; Nas, 1983; Van Hell \& De Groot, 1998; Van Heuven, Dijkstra, \& Grainger, 1998).

Several factors, however, seem to influence whether a bilingual's actual performance is more or less specific with respect to language (Grosjean, 1997). In studying the influence of nontarget-language knowledge on targetlanguage performance, at least three factors are important: (1) task demands and experimental stimulus materials, (2) the bilingual's linguistic expectations regarding which languages will be relevant for responding, and (3) the bilingual's relative language fluency. We will discuss these factors below and describe how we manipulated them in our experiments.

The first factor pertains to the task demands (Are one or both languages required to perform the task?) and to the language of the stimulus materials (Are bilinguals shown stimuli in only one language or in both languages during the experiment?). Previous studies, all of whose results were interpreted in terms of the language-nonselective view, differed in the languages that were relevant for task performance and/or the languages of the stimuli with which bilinguals were presented. In some studies, bilinguals were shown stimuli in both languages, and they had to respond to items from both languages (e.g., Dijkstra et al., 1998, Experiments 2 and 3; Grainger \& Beauvillain, 1987) or only to items from one language (e.g., Beauvillain \& Grainger, 1987; Bijeljac-Babic et al., 1997; Van Heuven et al., 1998). For example, in progressive demasking and lexical decision experiments involving Dutch-English bilinguals, Van Heuven et al. presented words with a high or a low number of orthographic neighbors in the target or in the nontarget language. They observed that the recognition of words in one language was affected by the number of their orthographic neighbors in both the target and the nontarget languages. These results were obtained not only under conditions in which stimulus presentation was mixed across languages, but also when stimulus presentation was blocked by language.

Other, and perhaps stronger, evidence for the notion that knowledge of one language influences performance in the other language is provided by studies in which the stimulus list and the task demands involved words from one target language only. By far the majority of these studies focused on performance in the second, and less dominant, language (L2; De Groot et al., 2000; Dijkstra et al., 1998; Nas, 1983; Van Heuven et al., 1998, Experiment 4). For example, Dijkstra et al. (1998, Experiment 1) had Dutch-English bilinguals perform a lexical decision task in their L2 (English) on a set of identical interlexical homographs (i.e., words with an identical spelling but different meanings across languages, such as room, meaning "cream" in Dutch), identical cognates (words with identical meanings and spellings across languages, such as lip), and matched controls. Lexical deci- sion times on the cognates were shorter than those on the matched controls, but no difference was observed between the homographs and their controls. The latter effect was recently replicated by De Groot et al. (2000, Experiment 2, Condition English). It can be argued, however, that the experimental contexts in these studies were not exclusively L2 contexts, because visually presented identical interlexical homographs or identical cognates are ambiguous in terms of the language to which they belong.

The most critical way to study whether knowledge of one language affects performance in the other language is to create an experimental context in which bilinguals perform a task exclusively in their dominant language (L1), and in which they are presented with L1 words. Although Caramazza and Brones (1979) and Gerard and Scarborough (1989) reported no effects of L2 knowledge on L1 word performance under such circumstances, some other authors did (Altenberg \& Cairns, 1983, Experiment 4; De Groot et al., 2000; Van Hell \& De Groot, 1998).

In a lexical decision experiment, Altenberg and Cairns (1983) had English-German bilinguals process words and nonwords that followed the orthographic and phonological rules in either L1 or L2, in both languages, or in neither of the two languages. The lexical decision times for the nonwords were affected by their legality in L1 as much as by their legality in L2. However, an effect of L2 on L1 processing was not observed in the word data. This limits one's ability to draw firm conclusions about the influence of nondominant language knowledge on dominant language word processing. Moreover, the lexical decision times for both types of nonwords did not differ from the lexical decision times for the words, which is surprising, given the typically shorter latencies for words than for nonwords in lexical decision (see Grosjean, 2001, for other questions regarding that study).

More recently, De Groot et al. (2000, Experiment 2, Condition Dutch) presented Dutch-English bilinguals with identical interlexical homographs and matched L1 control words. The lexical decision times on homographs were significantly longer than those on matched control words, though only for homographs with a higher frequency in English than in Dutch. As stated above, however, it can be argued that interlexical homographs are ambiguous with respect to the language to which they belong.

Finally, in a naming experiment with English-French bilinguals, Jared and Kroll (2001) compared performance on English words with word bodies that (1) were consistent in English and did not occur in French (no-enemies), (2) were consistent in English but were pronounced differently when they appeared in French words (French enemies), or (3) were inconsistent in English and did not occur in French (English enemies). Jared and Kroll observed no differences in naming latencies for French enemies and no-enemies in English-dominant bilinguals, although the proficient French-dominant bilinguals in 
their study made more errors on French enemies than on no-enemies.

In the studies we report in the present paper, the experiments provided an exclusive L1 context. Our bilinguals (or, rather, trilinguals; see below) were presented with word stimuli in their dominant language, L1, and performed a task in their L1. One set of L1 words had a cognate relationship with their translations (e.g., the Dutch bakker, meaning "baker") and one set consisted of noncognates (e.g., the Dutch tuin, meaning "garden"). The majority of the cognates were nonidentical cognates, and hence, they were unambiguous with respect to the language to which they belonged.

The second factor in the discussion of whether knowledge of one language affects performance in the other language concerns the bilingual's expectations as to which language or languages will be relevant in the communicative setting at hand. These language expectations are central to Grosjean's (1997) concept of language modes, which maintains that the activation of the language systems of a bilingual (or multilingual) depends on the language mode that the person is in at that time. In the monolingual mode, the bilingual interacts with others in one language, while the other language is deactivated. In the bilingual mode, the bilingual chooses a base language, but the other language remains active and can be called on from time to time, as is exemplified by language mixing. An important implication is that if the experimental context induces a bilingual language mode-for example, by presenting stimuli in both languages or because bilinguals know that their knowledge of two languages is crucial to the experiment-words in both language systems will be activated. In other words, not controlling the language mode may affect the activation of the nontarget language when a word in the target language is processed (Grosjean, 1997). In the experiments that we report in the present paper, we explicitly aimed to bring the participants into a monolingual mode-namely, the native language mode. The task and the stimulus materials did not explicitly refer to the participants' foreign language knowledge. Moreover, we used a selection procedure by which the participants could not know that we were interested in their foreign language knowledge (in particular in Experiments 1 and 2; see Method sections for more details).

The third factor that influences the interaction of the bilingual's two languages is his or her relative fluency in the two languages. Relative language fluency will affect the bilingual's sensitivity to L1 interference when he/she is processing in $\mathrm{L} 2$, and the sensitivity to $\mathrm{L} 2$ interference when processing in $\mathrm{L} 1$. The underlying rationale here is that less activation is needed to recognize words that are used relatively frequently, as are words in a language in which the speaker is relatively proficient. Previous studies have shown that processing in the weaker language, L2, can be influenced by knowledge of the stronger language, L1 (e.g., Bijeljac-Babic et al., 1997; De Groot et al., 2000; Dijkstra et al., 1999; Dijkstra et al., 1998; Nas, 1983; Van Heuven et al., 1998). In a divergence from previous studies, we examined whether knowledge of a weaker language (L2) would influence performance on words in the dominant language (L1). What is more, we studied the role of nontarget language proficiency in greater detail by manipulating the subjects' proficiency in the nontarget languages. This was done by testing trilinguals. In the first two experiments, the trilinguals were most fluent in their L1 (Dutch), somewhat less fluent in their L2 (English), and least fluent in their third and weakest language, L3 (French). In the third experiment, we tested trilinguals with a higher level of fluency in L3 (French). These trilinguals' fluency levels in L2 and L3 were comparable, unlike the L2 and L3 fluency levels of the trilinguals tested in Experiments 1 and 2.

In terms of the three factors discussed above, the setup of our experiments constitutes the most extreme test of whether word processing in one language is affected by nontarget language knowledge. First, the trilinguals were presented with L1 stimuli only and performed a task in $\mathrm{L} 1$, and we examined the influence of weaker language knowledge on performance in the dominant language. Second, the communicative setting induced a monolingual, native language mode. Third, we looked more closely at the role of relative language fluency by manipulating the proficiency of nontarget language knowledge.

The crucial manipulation of the stimulus words in all experiments concerned their cognate status: One quarter of the L1 words were cognates with their translations in English (L2), one quarter of the L1 words were cognates with their translations in French (L3), and the remaining words were noncognates. If nontarget language knowledge is activated and influences performance in the target language (here, L1), performance should lead to different result patterns for cognates than for noncognates. If the influence of one language on the other is qualified by nontarget language proficiency, the trilinguals' performance on the cognates with English or on the cognates with French should depend on their foreign language fluency level. Specifically, an effect of cognate status might only be obtained when proficiency in the nontarget language is relatively high.

We tested the effects of L2 and L3 on L1 with two experimental tasks: a word association task (Experiment 1) and a lexical decision task (Experiments 2 and 3). The latter task, considered to reflect word perception, is the experimental task most frequently used to study the interaction between languages in bilingual processing. When performing this task, bilinguals (and monolinguals) appear to use three types of information: orthographic, phonological, and semantic (see, e.g., Balota, Ferraro, \& Connor, 1991; Dijkstra et al., 1999). The word association task, used less frequently in bilingual research, is a production task, engaging the full spoken-language production apparatus. In word association, the person first has to identify a word, thereby presumably activating a 
word's orthographic, phonological, and semantic information. In the subsequent activation and production of an associate, semantic information seems to play an important role (Van Hell \& De Groot, 1998). An inspection of the actual associative responses given, as listed by De Groot (1989) and Postman and Keppel (1970), revealed that most associations to nouns are related in meaning to the presented stimulus word (see Van Hell \& De Groot, 1998, for more details). Using the word association task with bilinguals, Van Hell and De Groot unexpectedly observed that association times to L1 words that were cognates with their L2 translations were shorter than those to noncognates. In Experiment 1, we used the word association task in a new experimental context, using a different sample of test stimuli and participants along with finetuned controls to study the influence of foreign language knowledge on native language processing.

\section{EXPERIMENT 1}

\section{Method}

Participants. Nineteen unbalanced trilinguals with Dutch as L1, English as L2, and French as L3 participated in the experiment. All were first-year psychology students of the University of Amsterdam. They were all native speakers of Dutch who had learned their foreign languages at school. At around age 10, they had started to learn English (U.K.) at primary school; their English classes were intensified at secondary school to about $3-4 \mathrm{~h}$ a week, for 6 years, starting at around age 12. They learned French at secondary school, $2-3 \mathrm{~h}$ a week, for 6 years. Their subsequent training at the university required them to read mainly in English.

To prevent the trilinguals from knowing in advance that we were interested in their foreign language knowledge, a careful selection procedure was followed. At the beginning of the school year, all first-year psychology students of the University of Amsterdam complete a large battery of pen-and-paper tests. In one of these tests, they are asked to fill in the subjects of their exams in secondary school. On the basis of this test we wrote a letter to all students $(N=150)$ who had taken final exams in Dutch, English, and French (Dutch and English are obligatory subjects and French is an optional subject in secondary school exams). We asked them whether they were interested in participating in a memory experiment, without making any reference to its multilingual nature. Of the 37 students who responded, 19 were allocated to Experiment 1. The remaining 18 students were allocated to Experiment 2. The trilinguals received course credit or were paid for their participation.

Materials. The stimulus materials consisted of 80 Dutch words (see Appendix). Twenty words were cognates with their English translations but not with their French translations. Hence, these Dutch words resembled their English translations in orthography, phonology, and meaning; examples are bakker (English baker, French boulanger) and droom (English dream, French rêve). Another 20 Dutch words were cognates with their French translations but not with their English translations; some examples are meubel (French meuble, English piece of furniture) and muur (French mur, English wall). All cognate translations had a nonidentical phonology, whereas $85 \%$ and $75 \%$ of the cognates with English and with French, respectively, had a nonidentical orthography. The remaining 40 Dutch words were noncognates, and resembled neither their English nor their French translation in either orthography or phonology; examples are tuin (English garden, French jardin) and schotel (English saucer, French soucoupe).

The three groups of words (i.e., cognates with English, cognates with French, and noncognates) were words for concrete concepts, and were controlled for length in letters $(M=5.4, S D=0.7 ; M=5.5$,
$S D=1.1 ; M=5.4, S D=1.0$, respectively), for $\log$ word frequency $(M=1.38, S D=0.40 ; M=1.17, S D=0.53 ; M=1.12, S D=0.60$, respectively), and for the number of orthographic neighbors in Dutch $(M=2.6, S D=2.4 ; M=2.6, S D=3.8 ; M=2.4, S D=2.2$, respectively). Log word frequencies were based on the CELEX printedlemma frequency counts (occurrences per million; Baayen, Piepenbrock, \& Van Rijn, 1993). The number of orthographic neighbors was assessed by three adult native Dutch speakers who, for each word, listed all words they could think of that differed in only one letter from the original word.

In addition to the test stimuli, 10 Dutch words, all different from any of the test stimuli, were selected as practice stimuli.

Apparatus and Procedure. The experiment was run on an Apple Macintosh computer. All participants were tested individually. They were instructed that on each trial a word would appear on the screen. They were asked to speak out loud, as quickly as possible, the first word that came into their mind upon reading the word on the screen.

The procedure for each trial was as follows. First, a fixation stimulus (an asterisk) appeared on the screen for $1 \mathrm{sec}$. Next, the target word was presented; it remained on the screen until the participant responded. The onset of the participant's response was registered by a microphone that activated a voice-operated switch. Reaction time (RT) was measured from the onset of the stimulus. The experimenter noted the response (not visible to the participant). Three seconds after stimulus offset, the next trial was presented. The maximum presentation duration for a stimulus was $5 \mathrm{sec}$. Whenever this period expired without a response, the experimenter noted down the word "none." Stimuli were presented in lowercase letters, in black on a white background.

Each participant completed 10 practice trials and 80 test trials. All trials were presented in random order, with a different order for each participant. The test trials were divided into 4 blocks of 20 stimuli each.

The trilinguals' different levels of proficiency in their two foreign languages enabled a study of the influence of relative foreign language fluency on the processing of words in the dominant language. Another reason for testing trilinguals was a methodological one. In our studies, three groups of words are compared. Such a between-items manipulation is a widely used procedure in language and memory research, but it requires careful matching of the stimuli on known confounding variables (as was done in the present work). Careful matching procedures, however, do not guarantee that stimuli are matched on all potentially relevant variables (cf. Forster, 2000). Typically, researchers cannot check the adequacy of their matching procedures, but an obvious solution in the present trilingual study would be to test a monolingual control group as well. The presence of a cognate effect in multilinguals and its absence in monolinguals would confirm that the observed cognate effect is a consequence of the multilingualism of the participants rather than of an incomplete match of cognates to control items. In the Netherlands, however, it is almost impossible to match multilinguals to a monolingual control group, because practically all native speakers of Dutch have at least a basic knowledge of English. The absence of this monolingual control group motivated us to test trilinguals and to manipulate relative language fluency within and across our trilingual participants in Experiments 1-3. If a cognate effect arises in these experiments that can be attributed to an experimental artifact, it should not be modulated by language fluency.

\section{Results and Discussion}

For each participant and for each item, mean word association RTs were calculated for the cognates with English, the cognates with French, and the noncognates. False registrations due to voice-switch registration errors ( $4.28 \%$ of all data) were excluded in calculating the means. Responses that were not initiated within $5 \mathrm{sec}$ 
after stimulus onset (i.e., response omissions) were also excluded. The resulting data are presented in Table 1.

One-factor analyses of variance (ANOVAs) were performed on mean RTs with participants $\left(F_{1}\right)$ and items $\left(F_{2}\right)$ as random variables. The effect of word type was significant $\left[F_{1}(2,36)=9.09, p<.001, F_{2}(2,77)=5.17\right.$, $p<.01]$. A Newman-Keuls test revealed that the mean association times to the L1 cognates with English were shorter than those to the L1 noncognates (participants, $p<.01$; items, $p<.05$ ). In contrast, the mean association times to the L1 cognates with French did not differ statistically from those to the noncognates (both $p s>.10$ ). Finally, the trilinguals were faster in associating to the L1 cognates with English than to the L1 cognates with French (participants, $p<.01$; items, $p<.05$ ).

The observation that word association times to L1 cognates with English are shorter than those to noncognates parallels a recent, and unexpected, finding of Van Hell and De Groot (1998). Though this study was designed for testing hypotheses other than those of the present paper, one group of Dutch-English bilinguals performed a word association task in L1 (Dutch). Using a different set of L1 cognates with English and noncognates, and a different group of participants, Van Hell and De Groot also obtained shorter association times to L1 cognates with English than to noncognates.

Proficiency tests. After completion of the word association task, the trilinguals performed proficiency tests in Dutch, English, and French. These tests were all lexical decision tasks, consisting of 50 words and 40 pseudowords in each of the three languages. The stimuli in each proficiency test were different from those in the other proficiency tests and from the stimuli of the experiment. The stimuli were controlled for length and for frequency. For each test, an additional 10 words and 8 pseudowords served as practice stimuli.

The apparatus of the lexical decision tests was similar to that of the word association task, with the exception that responses were registered with a two-button keyboard; the right button was pressed in the case of a word, and the left button in the case of a nonword. The order of the three tests was alternated across the participants. Trials were presented in random order, with a different order for each participant.

For each participant and for each item, mean RTs were calculated for the words on each of the three proficiency tests. Response times of incorrect responses (Dutch,
0.84\%; English, 6.21\%; French, 23.11\%) and those shorter than $100 \mathrm{msec}$ and $2.5 S D$ above the mean (Dutch, 2.84\%; English, 2.53\%; French, 2.67\%) were eliminated. One-factor ANOVAs on the RT data revealed a significant effect of language $\left[F_{1}(2,36)=118.07, p<.0001\right.$, $\left.F_{2}(2,147)=97.33, p<.0001\right]$. A Newman-Keuls test verified that the trilinguals were most fluent in Dutch $(M=507 \mathrm{msec}, S D=41)$, somewhat less fluent in English $(M=601 \mathrm{msec}, S D=54)$, and least fluent in French $(M=685 \mathrm{msec}, S D=69)$; for all differences, $p<.01$.

In the second experiment, the stimuli of Experiment 1 were presented to a new group of Dutch-English-French trilinguals, who performed a lexical decision task.

\section{EXPERIMENT 2}

\section{Method}

Participants. A new group of 18 Dutch-English-French trilinguals, selected via the procedure described in Experiment 1, participated in the experiment. They received course credit or were paid for their participation.

Materials, Apparatus, and Procedure. The stimulus words were similar to those used in Experiment 1. Sixty pseudowords were created by changing one letter of newly selected words. The pseudowords did not differ in length from the word stimuli. An additional 20 words and 15 pseudowords were selected to serve as practice trials.

The apparatus and procedure of the lexical decision task were similar to those of the proficiency tests described in Experiment 1.

Each participant completed 35 practice trials and 140 test trials. The test trials were divided into 4 blocks of 35 stimuli each.

\section{Results and Discussion}

For each participant and for each item, mean RTs were calculated for the cognates with English, for the cognates with French, and for the noncognates. RTs of incorrect responses and those shorter than $100 \mathrm{msec}$ and $2.5 \mathrm{SD}$ above the mean $(2.71 \%$ of all data) were discarded. Data on the pseudowords, requiring a "no" response, were regarded as fillers and are not reported here. Mean lexical decision times and errors are presented in Table 1.

One-factor ANOVAs were performed on the mean correct RTs with participants $\left(F_{1}\right)$ and items $\left(F_{2}\right)$ as random variables. The effect of word type was significant $\left[F_{1}(2,34)=6.90, p<.005, F_{2}(2,77)=3.51, p<.05\right] . \mathrm{A}$ Newman-Keuls test showed that the mean lexical decision times to the L1 words that were cognates with English were shorter than those to the noncognates (participants, $p<.01$; items, $p<.05)$. Mean lexical decision times

Table 1

Mean Reaction Times (RTs, in Milliseconds) and Omission Scores (in Percentages) of the Word Association Task (Experiment 1), and Mean Reaction Times and Errors (in Percentages) of the Lexical Decision Task (Experiment 2) for Cognates with English, Cognates with French, and Noncognates

\begin{tabular}{|c|c|c|c|c|c|c|c|c|}
\hline \multirow[b]{2}{*}{ Stimulus } & \multicolumn{4}{|c|}{ Word Association (Experiment 1) } & \multicolumn{4}{|c|}{ Lexical Decision (Experiment 2) } \\
\hline & RT & $S D$ & Omission (\%) & $S D$ & RT & $S D$ & Error $(\%)$ & $S D$ \\
\hline Cognates, English & 1,641 & 373 & 2.11 & 5.6 & 499 & 48 & 1.94 & 3.0 \\
\hline Cognates, French & 1,809 & 317 & 3.16 & 6.1 & 519 & 46 & 2.50 & 3.5 \\
\hline Noncognates & 1,845 & 304 & 3.29 & 6.1 & 529 & 41 & 7.36 & 3.7 \\
\hline
\end{tabular}

Note-All means presented are based on participants' scores. 
for the L1 words that were cognates with French were statistically similar to those for the noncognates (both $p \mathrm{~s}>$ .10). The difference between the L1 words that were cognates with English and the L1 words that were cognates with French reached significance on the analysis by participants $(p<.05)$, but not on the analysis by items.

Proficiency tests. After finishing the lexical decision task, the participants performed three proficiency tests. The materials, apparatus, and procedure of the proficiency tests were identical to those of Experiment 1. For each participant and for each item, mean RTs were calculated for the words of each of the three proficiency tests. RTs of incorrect responses (Dutch, 3.78\%; English, $8.89 \%$; French, 23.22\%) and RTs shorter than $100 \mathrm{msec}$ and $2.5 S D$ above the mean (Dutch, 2.44\%; English, $2.22 \%$; French, $2.22 \%$ ) were discarded. One-factor ANOVAs on the RT data revealed a significant effect of language $\left[F_{1}(2,34)=85.53, p<.0001, F_{2}(2,147)=\right.$ $92.88, p<.0001]$. A Newman-Keuls test verified that the trilinguals were most fluent in Dutch $(M=471 \mathrm{msec}$, $S D=31)$, somewhat less fluent in English $(M=550 \mathrm{msec}$, $S D=43)$ and least fluent in French $(M=611 \mathrm{msec}, S D=$ $64)$; for all differences, $p<.01$.

The lexical decision experiment, like the word association experiment, shows that processing words in the strongest language can be influenced by weaker language knowledge - in this case, L2 knowledge. The manipulation of the trilinguals' proficiency in L2 and L3 revealed, however, that their fluency in L3 was too weak to exert any effect on L1 processing.

An implication of the preceding observation is that weaker language knowledge may influence performance in the dominant language as multilinguals gain more fluency in the weaker language. Hence, the native language performance of our trilinguals who were relatively fluent in L3 may be sensitive to L3 knowledge, at least more so than in the case of trilinguals who were less fluent in L3. To see whether our data confirm this prediction, we selected the four most fluent and the four least fluent L3 speakers on the basis of their performance on the L3 (i.e., French) proficiency test. Indeed, for the most fluent French speakers, the mean lexical decision time on the cognates with French $(485 \mathrm{msec})$ was $26 \mathrm{msec}$ shorter than that on the noncognates $(511 \mathrm{msec})$. In the least fluent French speakers, however, the mean lexical decision time on the cognates with French $(551 \mathrm{msec})$ approached that on the noncognates $(556 \mathrm{msec})$.

In order to strengthen the interpretation of this post hoc analysis and our conclusion that L1 performance can be influenced by weaker language knowledge if the multilingual has reached a certain level of weaker language fluency, we performed a third study, using trilinguals with a higher level of proficiency in L3, French.

\section{EXPERIMENT 3}

\section{Method}

Participants. A group of 21 Dutch-English-French trilinguals were recruited from the French Language and Literature Department of the University of Nijmegen.
In Experiments 1 and 2, we used trilingual psychology students who had taken final exams in English and French at secondary school. In Experiment 3, we wanted to test trilinguals who were comparable to those of Experiments 1 and 2, but with a higher level of fluency in French. Hence, we had to recruit students from the French Language and Literature Department. They were recruited by a student of French enrolled in an optional course in experimental psychology, who ran Experiment 3 for course credit. The experimenter told potential participants that she was running a psychology experiment to obtain course credit in the Psychology department, and invited them to the psychology lab. She did not tell the participants that their foreign language knowledge was important. After the experiment, they were asked about their perceptions of the nature of the experiment. All participants thought they would be participating in a psychology experiment, and they were unaware of the importance of their foreign language knowledge to the experimental task. ${ }^{1}$

The participants were paid for their participation.

Materials, Apparatus, and Procedure. The materials and procedure were identical to those used in Experiment 2 (the critical stimuli were identical across all experiments), and the apparatus was comparable to that used in Experiment 2.

\section{Results and Discussion}

The procedure used in Experiment 2 was used in Experiment 3 to calculate mean RTs for the cognates with English, for the cognates with French, and for the noncognates. RTs of incorrect responses and those shorter than $100 \mathrm{msec}$ and $2.5 S D$ above the mean $(2.68 \%$ of all data) were discarded. Mean lexical decision times and errors are presented in Table 2.

One-factor ANOVAs were performed on the mean correct RTs with participants $\left(F_{1}\right)$ and items $\left(F_{2}\right)$ as random variables. The effect of word type was significant $\left[F_{1}(2,40)=13.28, p<.0001, F_{2}(2,77)=6.61, p<.005\right]$. Importantly, the Newman-Keuls test showed that the mean lexical decision times to the L1 words that were cognates with French were shorter than those to the noncognates (participants, $p<.05$; items, n.s, $p=.14$ in a one-factor ANOVA on the item means of the cognates with French and the noncognates). Likewise, mean lexical decision times to the L1 words that were cognates with English were shorter than those to the noncognates (both $p \mathrm{~s}<.01$ ). The difference between the L1 words that were cognates with French and the L1 words that were cognates with English also reached significance (participants, $p<.01$; items, $p<.05$ ).

Proficiency tests. After finishing the experiment, the participants performed three proficiency tests. The materials were identical to those used in Experiments 1 and 2, but we replaced four nonwords in the French proficiency

Table 2

Mean Reaction Times (RTs, in Milliseconds) and Errors (in Percentages) of the Lexical Decision Task (Experiment 3) for Cognates with English, Cognates with French, and Noncognates

Lexical Decision (Experiment 3)

\begin{tabular}{llccc}
\cline { 2 - 5 } \multicolumn{1}{c}{ Stimulus } & RT & $S D$ & Error (\%) & $S D$ \\
\hline Cognates, English & 489 & 60 & 2.14 & 2.5 \\
Cognates, French & 520 & 75 & 1.67 & 2.4 \\
Noncognates & 541 & 94 & 2.50 & 1.6 \\
\hline
\end{tabular}

Note-All means presented are based on participants' scores. 
test that appeared to be words of low frequency. The procedure and apparatus were comparable to those used in Experiments 1 and 2. For each participant and for each item, mean RTs were calculated for the words of each of the three proficiency tests. ${ }^{2}$ Response times of incorrect responses (Dutch, 1.40\%; English, 7.50\%; French, $2.30 \%$ ) and RTs shorter than $100 \mathrm{msec}$ and $2.5 S D$ above the mean (Dutch, 2.40\%; English, 3.10\%; French, 2.90\%) were discarded. One-factor ANOVAs on the RT data revealed a significant effect of language $\left[F_{1}(2,38)=25.98\right.$, $\left.p<.0001, F_{2}(2,147)=24.35, p<.0001\right]$. A NewmanKeuls test verified that the trilinguals were most fluent in Dutch $(M=501 \mathrm{msec}, S D=62$; both $p$ s $<.01)$ and equally fluent in French and English $(M=560 \mathrm{msec}$, $S D=65$ and $M=567 \mathrm{msec}, S D=57$, respectively).

\section{GENERAL DISCUSSION}

In Experiments 1 and 2, Dutch-English-French trilinguals who were most fluent in L1, less fluent in L2, and least fluent in L3 performed a word association or a lexical decision task in their native and dominant language, $\mathrm{L} 1$, in a list context that exclusively involved presentation of L1 words. Even though these tasks may be assumed to differ considerably in their component processes, the patterns of results in the two experiments were highly similar: Word association and lexical decision times for words that were cognates with their L2 translations were shorter than those for the noncognates. No cognate advantage was obtained, however, with stimuli that were cognates with their translations into the trilinguals' third and weakest language. In Experiment 3, the same materials were tested with trilinguals having a higher level of fluency in L3 (i.e., they were equally fluent in L2 and in L3). Now, a cognate advantage arose not only in words that were cognates with their L2 translations, but also in words that were cognates with their L3 translations.

These findings have a number of important implications for the activation and organization of words in multilingual memory, which we will discuss now. The main points of this discussion touch upon the three factors that were mentioned in the introduction-namely, the exclusively native language context of our experiments, the participants' language expectations and language mode, and their relative language fluency.

\section{Exclusively Native Language Context of the Experiments}

Our finding that foreign language knowledge affects L1 target word processing in an exclusively native language context provides strong support for the theoretical position that the language processing system of multilinguals is profoundly nonselective with respect to language. Presentation of a word in one language automatically activates words from both the target and the nontarget language in parallel. Previous work by De Groot et al. (2000), Dijkstra et al. (1998), Nas (1983), and Van Heuven et al. (1998) has already suggested that processing a weaker language (L2) word or pseudoword entails auto- matic, parallel activation of candidate words in the dominant, stronger language (L1). Our study strengthens and extends this position in an important way, because it indicates that such automatic, parallel activation of candidate words also holds for the reverse situation: The recognition of L1 input words was found to be affected by the presence of L2 word candidates that were cognates with the L1 targets. This finding indicates that the L1, as the first and dominant language, does not have a special, invulnerable status relative to other languages.

Most remarkably, the effect on L1 target words was found even though the majority of the cognates in our experiments were nonidentical across languages in terms of both their orthography and their phonology (e.g., bakker-baker and meubel-meuble). Unlike in many previous studies, in which identical cognates or identical homographs were used (e.g., De Groot et al., 2000; Dijkstra et al., 1998), our stimuli were unambiguous with respect to the language to which they belonged. ${ }^{3}$

The manipulation of the multilinguals' proficiency in their second and third languages qualified the emergence of effects of weaker language knowledge on native language processing: Activation of weaker language knowledge was only noticeable when the speaker was relatively fluent in the nonnative language.

Theoretically, our data are best described by assuming a language-nonselective access process in which word candidates from both languages are activated in parallel. Native language input words coactivate candidate words in the other, nontarget language, most likely words that are highly similar in orthography, semantics, and phonology. The convergent activation of cognate translations (such as bakker and baker) in terms of these codes may benefit the activation of cognates compared to that of noncognates (such as tuin and garden), leading to faster lexical decision times for the cognates. Likewise, because of the earlier convergence of activation of cognates in comparison with noncognates, semantically related words become activated sooner in the case of cognates than in that of noncognates, and lead to faster associative responses to cognates than to noncognates (for more details, see Van Hell \& De Groot, 1998).

There is a growing body of evidence that cognates indeed have a special type of representation in the mental lexicon (e.g., De Groot \& Nas, 1991; Sánchez-Casas, Davis, \& García-Albea, 1992), and that the result patterns we obtained are not just a consequence of cumulative frequency effects (see also De Groot et al., 2000; Dijkstra et al., 1999) or language-independent global activation (cf. De Groot et al., 2000). First, given that most cognates in our study had a different orthographic representation in the two languages (e.g., bakker vs. baker), it seems unlikely that the effects can be explained by assuming that a cognate's effective frequency is simply that of the sum of the frequencies of two words across languages. ${ }^{4}$ Second, our association data also hint at different representations for cognates than for noncognate controls, at least at the semantic level. It is hard to see how different association patterns could be a conse- 
quence of a higher global activation or summed frequency for cognates than for noncognates.

Other recent studies also provide arguments against global activation, even when it would be language nonselective (activating lexical candidates in both languages). Dijkstra et al. (1998, Experiment 1) found that, in lexical decision, orthographically identical cognates led to facilitation effects relative to English control words in Dutch-English bilinguals, even though interlingual homographs did not. Because, like cognates, interlingual homographs also have readings in two languages, mere global activation cannot account for the cognate facilitation effect. This conclusion is further supported by the comparison of cognate and interlingual homograph recognition in Dijkstra et al. (1999), who demonstrated that effects of semantic and orthographic overlap resulted in facilitation effects for both types of items, whereas phonological overlap induced inhibition. This result directly opposes the argument of global activation, which should be larger when phonological overlap is present. Furthermore, this study also clearly indicates that it is semantic overlap that leads to the generally larger effects for cognates than for homographs.

\section{Language Expectation and Language Mode}

According to the language mode concept discussed in the introduction, the relative activation (and thus the degree of language selectivity) of bilinguals' or multilinguals' language systems depends on whether they find themselves in a more monolingual or bilingual language situation (Grosjean, 1997). This view entails a certain degree of control by bilinguals over the activation of words in their languages. Bilinguals who are in a monolingual mode will be able to deactivate (or even inhibit; see Green, 1998) nontarget-language words. In our study, we explicitly aimed to bring the trilinguals into a monolingual, native-language mode: They were unaware of our interest in their foreign language knowledge and were presented with words of their native language only. Their performance was nevertheless influenced by foreign language knowledge, suggesting that activation of words in the weaker language occurs automatically and bottom-up, thereby at least overriding control mechanisms pertaining to deactivation or inhibition of nontarget-language words (should such mechanisms indeed be present). Thus, as a first systematically controlled test of the language mode hypothesis, the present study provides some evidence against a strict interpretation of this hypothesis.

\section{Relative Fluency in the Second and Third Languages of the Trilinguals}

In Experiments 1 and 2, trilinguals were tested with different levels of fluency in the nontarget languages: L2 (English) and L3 (French). We observed that strongestlanguage processing was influenced by nontargetlanguage knowledge (i.e., L2 knowledge), but that their fluency in L3 was too weak to exert a significant effect on L1 processing. In Experiment 3 we increased the level of fluency in L3 by testing trilinguals that were equally fluent in L2 and L3. We then observed that processing in L1 was influenced by L2 and L3 nontarget language knowledge. These combined effects also indicate that the cognate facilitation effects we observed are related to relative language fluency, and are not an artifact of the stimulus materials.

The findings resulting from the nontarget, and weaker, language fluency manipulation thus set limits on the size of cross-linguistic effects. We propose that the access and activation of words in the bilingual or trilingual memory system is nonselective with respect to language, but that a certain level of weaker language fluency is required before any weaker language effects become noticeable in L1 processing. Moreover, our manipulation of nontarget language proficiency hints at why some studies did not find an influence of nontarget language knowledge on target language processing (e.g., Caramazza \& Brones, 1979; Gerard \& Scarborough, 1989; Jared \& Kroll, 2001, Experiments 1-2; Kirsner, Smith, Lockhart, King, \& Jain, 1984; Scarborough, Gerard, \& Cortese, 1984). The bilinguals' nontarget language proficiency, relative to their target language proficiency, may have been too low to induce any noticeable effects on target language processing.

\section{Consequences for Models of Bilingual Lexical Processing}

The present results support language-nonselective access models of bilingual word recognition, such as the BIA and the BIA ${ }^{+}$models (Dijkstra \& Van Heuven, 2002; Van Heuven et al., 1998) and the IC model (Green, 1998). However, whether these models can really account for our finding of substantial cognate facilitation effects in a stimulus set with a high number of nonidentical cognates remains to be seen. For instance, due to the presence of lateral inhibition in the BIA model, cognates that are similar but nonidentical in orthographic form across languages should lead to much smaller facilitation effects than should form-identical cognates (cf. Dijkstra et al., 1999; Van Heuven et al., 1998). Alternatively, the results might be explained with distributed models of bilingual processing (e.g., Thomas, 1997; Thomas \& Allport, 2000), which allow for noncatastrophic transitions in behavior between form-identical and -nonidentical items. Future studies should more directly contrast performance on these two types of items (see Font, 2001, for a first study involving nonidentical French-Spanish cognates).

To conclude, our study showed that even when multilinguals function in a native language context and are unaware of the experiment's multilingual nature, native language performance can be influenced by the knowledge of a weaker language, provided that fluency in the weaker language is relatively high. These results support the theoretical position that multilinguals' processing system is profoundly nonselective with respect to language. In a language-nonselectiveword recognition system, presented words from either language activate lexical candidates in both the target and the nontarget languages. From this it 
logically follows that cross-linguistic effects may arise in both directions, manifesting themselves not only in a nondominant but also in a dominant target language.

\section{REFERENCES}

Altenberg, E. P., \& Cairns, H. S. (1983). The effects of phonotactic constraints on lexical processing in bilingual and monolingual subjects. Journal of Verbal Learning \& Verbal Behavior, 22, 174-188.

BaAyen, H., Piepenbrock, R, \& Van Rijn, H. (1993). The CELEX lexical database (CD-ROM). Philadelphia: University of Pennsylvania, Linguistic Data Consortium.

Balota, D. A., Ferraro, F. R., \& Connor, L. T. (1991). On the early influence of meaning in word recognition: A review of the literature. In P. J. Schwanenflugel (Ed.), The psychology of word meanings (pp. 187-222). Hillsdale, NJ: Erlbaum.

Beauvillain, C., \& Grainger, J. (1987). Accessing interlexical homographs: Some limitations of a language-selective access. Journal of Memory \& Language, 26, 658-672.

BiJelJaC-BABic, R., BiardeaU, A., \& Grainger, J. (1997). Masked orthographic priming in bilingual word recognition. Memory \& Cognition, 25, 447-457.

Brysbaert, M., Van Dyck, G., \& VAn de Poel, M. (1999). Visual word recognition in bilinguals: Evidence from masked phonological priming. Journal of Experimental Psychology: Human Perception \& Performance, 25, 137-148.

Caramazza, A., \& Brones, I. (1979). Lexical access in bilinguals. Bulletin of the Psychonomic Society, 13, 212-214.

De Groot, A. M. B. (1989). Representational aspects of word imageability and word frequency as assessed through word association. Journal of Experimental Psychology: Learning, Memory, \& Cognition, 15, 824-845.

De Groot, A. M. B., Delmaar, P., \& Lupker, S. J. (2000). The processing of interlexical homographs in translation recognition and lexical decision: Support for nonselective access to bilingual memory. Quarterly Journal of Experimental Psychology, 53A, 397-428.

De Groot, A. M. B., \& NAs, G. L. J. (1991). Lexical representation of cognates and noncognates in compound bilinguals. Journal of Memory \& Language, 30, 90-123.

Dijkstra, A., Grainger, J., \& Van Heuven, W. J. B. (1999). Recognition of cognates and interlingual homographs: The neglected role of phonology. Journal of Memory \& Language, 41, 496-518.

Dijkstra, A., \& Van Heuven, W. J. B. (2002). The architecture of the bilingual word recognition system: From identification to decision. Bilingualism: Language \& Cognition, 5, 175-197.

Dijkstra, A., Van JaArsveld, H., \& Ten Brinke, S. (1998). Interlingual homograph recognition: Effects of task demands and language intermixing. Bilingualism: Language \& Cognition, 1, 51-66.

Font, N. (2001). Rôle de la langue dans l'accès au lexique chez les bilingues: Influence de la proximité orthographiqueet sémantiqueinterlangue sur la reconnaissance visuelle de mots [The role of language in lexical access in bilinguals: Influence of interlingual orthographic and semantic proximity on visual word recognition]. Unpublished doctoral thesis, Université Paul Valery, Montpellier, France.

FORSTER, K. I. (2000). The potential for experimenter bias effects in word recognition experiments. Memory \& Cognition, 28, 1109-1115.

Gerard, L. D., \& Scarborough, D. L. (1989). Language-specific lexical access of homographs by bilinguals. Journal of Experimental Psychology, 15, 305-315.

Gollan, T. H., Forster, K. I., \& Frost, R. (1997). Translation priming with different scripts: Masked priming with cognates and noncognates in Hebrew-English bilinguals. Journal of Experimental Psychology: Learning, Memory, \& Cognition, 23, 1122-1139.

Grainger, J., \& BeAuvillain, C. (1987). Language blocking and lexical access in bilinguals. Quarterly Journal of Experimental Psychology, 39A, 295-319.

Grainger, J., \& Frenck-Mestre, C. (1998). Masked priming by translation equivalents in proficient bilinguals. Language \& Cognitive Processes, 13, 601-623.
Green, D. W. (1998). Mental control of the bilingual lexico-semantic system. Bilingualism: Language \& Cognition, 1, 67-81.

Grosjean, F. (1997). Processing mixed language: Issues, findings, and models. In A. M. B. de Groot \& J. F. Kroll (Eds.), Tutorials in bilingualism: Psycholinguistic perspectives (pp. 225-254). Mahwah, NJ: Erlbaum.

Grosjean, F. (2001). The bilingual's language modes. In J. L. Nicol (Ed.), One mind, two languages: Bilingual language processing (pp. 1-22). Oxford, U.K.: Basil Blackwell.

JARED, D., \& KROLL, J. F. (2001). Do bilinguals activate phonological representations in one or both of their languages when naming words? Journal of Memory \& Language, 44, 2-31.

JIANG, N. (1999). Testing processing explanations for the asymmetry in masked cross-language priming. Bilingualism: Language \& Cognition, 2, 59-75.

Kirsner, K., Smith, M. C., Lockhart, R. S., King, M. L., \& Jain, M. (1984). The bilingual lexicon: Language-specific units in an integrated network. Journal of Verbal Learning \& Verbal Behavior, 23, 519-539.

NAs, G. (1983). Visual word recognition in bilinguals: Evidence for a cooperation between visual and sound based codes during access to a common lexical store. Journal of Verbal Learning \& Verbal Behavior, 22, 526-534.

Postman, L., \& Keppel, G. (1970). Norms of word association. New York: Academic Press.

Sánchez-Casas, R. M., Davis, C. W., \& García-Albea, J. E. (1992). Bilingual lexical processing: Exploring the cognate/noncognate distinction. European Journal of Cognitive Psychology, 4, 293-310.

Scarborough, D. L., Gerard, L., \& Cortese, C. (1984). Independence of lexical access in bilingual word recognition. Journal of Verbal Learning \& Verbal Behavior, 23, 84-99.

Thomas, M. S. C. (1997). Connectionist networks and knowledge representation: The case of bilingual lexical representations. Unpublished doctoral thesis, University of Oxford.

Thomas, M. S. C., \& Allport, A. (2000). Language switching costs in bilingual visual word recognition. Journal of Memory \& Language, 43, 44-66.

VAn Hell, J. G., \& De Groot, A. M. B. (1998). Conceptual representation in bilingual memory: Effects of concreteness and cognate status in word association. Bilingualism: Language \& Cognition, 1, 193-211.

Van Heuven, W. J. B., Dijkstra, A., \& Grainger, J. (1998). Orthographic neighborhood effects in bilingual word recognition. Journal of Memory \& Language, 39, 458-483.

\section{NOTES}

1. In Experiments 1 and 2, we sent an invitation letter to trilinguals on the basis of a test in which they had filled in their final exam subjects. Hence, these trilinguals did not know in advance that we were interested in their foreign language knowledge. In Experiment 3, we tested trilinguals with a higher level of fluency in French, and could not use the careful selection procedure of Experiments 1 and 2 .

2. Due to technical failures, one participant's proficiency data were lost.

3 . Our study shows that the manipulation of cognate status is sensitive enough to detect influences of weaker language knowledge on L1 performance. It may be that such influences can only be traced using stimuli that share many features across languages, such as our cognates. This explanation may account for the absence, or relatively small size, of such effects in studies manipulating only phonological and/or orthographic features of stimuli (e.g., Altenberg \& Cairns, 1983; Jared \& Kroll, 2001).

4. Dijkstra et al. (1998, Experiment 3) obtained evidence for interlingual homographs that directly opposes the assumption of summed frequency effects for such items. Dutch-English bilinguals performed a generalized lexical decision task and responded with "yes" to words, irrespective of whether they belong to L1 or L2. Responses to interlingual homographs with a low frequency in English were slower, rather than faster, than those to matched Dutch control items. 


\section{APPENDIX}

Dutch Words Used in the Experiments; English and French Translations in Parentheses

\section{Cognates with English}

adder (adder, vipère); appel (apple, pomme); bakker (baker, boulanger); brood (bread, pain); bruid (bride, mariée); donder (thunder, orage); doof (deaf, sourd); droog (dry, sec); droom (dream, rêve); duivel (devil, diable); hamer (hammer, marteau); honing (honey, miel); nagel (nail, ongle); ring (ring, bague); schaap (sheep, mouton); schoen (shoe, chaussure); sneeuw (snow, neige); vuist (fist, poing); winter (winter, hiver); zilver (silver, argent).

\section{Cognates with French}

ananas (pineapple, ananas); beton (concrete, béton); ceintuur (belt, ceinture); citroen (lemon, citron); etappe (leg, étape); fabriek (factory, fabrique); feest (party, fête); gazon (lawn, gazon); gratis (free, gratuit); grot (cave, grotte); haven (harbour, havre); kado (present, cadeau); meubel (furniture, meuble); muur (wall, mur); plafond (ceiling, plafond); stage (apprenticeship,stage); taart (cake, tarte); tante (aunt, tante); tint (complexion, teint); triest (sad, triste).

\section{Noncognates}

aardig (kind, gentil); afwas (dishes, vaisselle); arts (doctor, médecin); beugel (brace, appareil); braam (blackberry, $\mathrm{m}^{\circ}$ re); boord (collar, col); breed (wide, large); dobber (float, flotte); erwt (pea, pois); fles (bottle, bouteille); haver (oats, avoine); kade (quay, quai); kelder (basement, cave); ketting (chain, chaîne); kraan (tap, robinet); krijt (chalk, craie); kogel (bullet, balle); lente (spring, printemps); lepel (spoon, cuiller); meeuw (gull, mouette); merel (blackbird, merle); nuchter (sober, sobre); oever (bank, rive); plamuur (filler, enduit); plavuis (tile, dalle); prut (grounds, marc); puist (pimple, bouton); romp (trunk, tronc); schotel (saucer, soucoupe); slager (butcher, boucher); staart (tail, queue); steeg (alley, ruelle); strand (beach, plage); stroef (rough, rude); tuin (garden, jardin); vierkant (square, carré); vlees (meat, viande); watten (cotton wool, coton); winst (profit, bénéfice); wortel (carrot, carotte). 